\title{
Cyclic plasticity and lifetime of the nickel-based Alloy C-263: Experiments, models and component simulation
}

\author{
G. Maier ${ }^{1, \text { a }}$, O. Hübsch ${ }^{1}$, H. Riedel ${ }^{1}$, C. Somsen ${ }^{2}$, J. Klöwer ${ }^{3}$, and R. Mohrmann ${ }^{4}$ \\ ${ }^{1}$ Fraunhofer Institute for Mechanics of Materials IWM, Woehlerstrasse 11, 79108 Freiburg, Germany \\ 2 Ruhr-Universität Bochum RUB, Universitaetsstrasse 150, 44801 Bochum, Germany \\ ${ }^{3}$ VDM Metals GmbH, Kleffstrasse 23, 58762 Altena, Germany \\ ${ }^{4}$ RWE Technology GmbH, Huyssenallee 12-14, 45128 Essen, Germany
}

\begin{abstract}
The present work deals with the thermomechanical fatigue and low-cycle fatigue behavior of C-263 in two different material conditions. Microstructural characteristics and fracture modes are investigated with light and electron microscopy. The experimental results indicate that viscoplastic deformations depend on the heat treatment or rather on the current state of the microstructure. The measured data are used to adjust the parameters of a Chaboche type model and a fracture-mechanics based model for fatigue lifetime prediction. The Chaboche model is able to describe the essential phenomena of time and temperature dependent cyclic plasticity including the complex cyclic hardening during thermo-cyclic loading of both material conditions with a unique set of material parameters. This could be achieved by including an additional internal variable into the Chaboche model which accounts for changes in the precipitation microstructure during high temperature loading. Furthermore, the proposed lifetime model is well suited for a common fatigue life prediction of both investigated heats. The deformation and lifetime models are implemented into a user defined material routine. In this work, the material routine is applied for the lifetime prediction of a critical power plant component using the finite element method.
\end{abstract}

\section{Introduction}

The nickel-based Alloy C-263 is a candidate for application in flexible next generation fossil fuel power plants. Furthermore, critical components in existing power plants could be substituted with thin-walled components made of C-263 material with the aim to increase the plant flexibility. In both cases the material must withstand numerous start-up and shut-down cycles in addition to the creep exposure during steady state operation. Thereby, temperature gradients and constrained thermal strains occur which lead to thermomechanical fatigue (TMF) of the material.

It is well known from other nickel base alloys that the microstructural evolution during high temperature application has a major influence on viscoplastic deformation and lifetime [1,2]. Treating the solution annealed material at $800{ }^{\circ} \mathrm{C}$ leads to the precipitation of carbides and $\gamma^{\prime}$-phase particles. Fatigue, creep and precipitation behavior of different age hardened C263 materials have been investigated by several other authors [3-5]. They developed physically based creep models considering the $\gamma^{\prime}$-precipitation. However, in case of fatigue, the authors used only standard plasticity models. The main focus of the present paper is the development of cyclic viscoplastic deformation

\footnotetext{
${ }^{a}$ Corresponding author: gerhard.maier@iwm.fraunhofer.de
}

Table 1. Chemical composition of C-263 as-received in wt $\%$.

\begin{tabular}{|l|l|l|l|l|l|l|}
\hline Ni & Cr & Co & Mo & Al & Ti & C \\
\hline bal. & 20.09 & 19.84 & 5.80 & 0.42 & 2.09 & 0.06 \\
\hline
\end{tabular}

and lifetime models that comprise the microstructural evolution of the material.

\section{Material and experimental}

C-263 is a solid solution strengthened and precipitation hardened material. Two different heat treatments of the nickel-based alloy C-263 were investigated: solution annealed (LG) and age hardened (AG). The solution annealed material was treated at $1145^{\circ} \mathrm{C}$ for 50 minutes and subsequently air cooled. The age hardened condition underwent additional four hours at $800^{\circ} \mathrm{C}$ and an air cooling. The chemical composition of the as-received material is shown in Table 1.

Figure 1 shows a light microscopy image of the solution annealed condition. Large titanium and nitrogen rich carbides inside the grains and smaller ones at grain boundaries are visible. After aging at $800^{\circ} \mathrm{C}$, secondary precipitates could be found inside the grain and at grain boundaries. Scanning transmission electron microscopy shows that grain boundaries exhibit chromium rich $\mathrm{M}_{23} \mathrm{C}_{6}$ carbides (see Figs. 2a, c). The diffraction pattern in the insert of Fig. $2 \mathrm{c}$ is attributed to titanium rich $\mathrm{M}_{7} \mathrm{C}_{3}$.

This is an Open Access article distributed under the terms of the Creative Commons Attribution License 4.0, which permits unrestricted use, distribution, and reproduction in any medium, provided the original work is properly cited. 


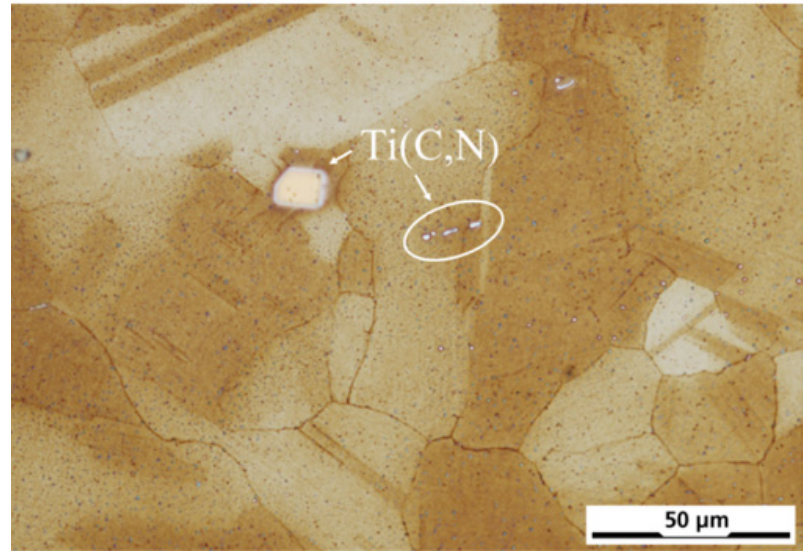

Figure 1. Light microscopy image of LG material, etched with Beraha II.

Furthermore, $\gamma^{\prime}$-precipitates could be detected inside the grains (Figs. 2b, d).

Various complex low-cycle fatigue (CLCF) and thermomechanical fatigue experiments were performed to characterize the viscoplastic deformation of the considered heats of C-263.

The isothermal CLCF tests were carried out at eight different temperatures in the range from room temperature to $900{ }^{\circ} \mathrm{C}$ in total strain control with a strain ratio $R_{\varepsilon}=-1$. A typical loading of a CLCF test comprising different strain rates, strain amplitudes and hold times in tension and compression is illustrated in Fig. 3. Due to this complex loading, strain dependent effects and the material relaxation behavior can be analyzed in one single experiment. The nominal strain rate of the cyclic part of the CLCF test was $10^{-3} \mathrm{~s}^{-1}$.

TMF tests were carried out with zero total strain in two temperature ranges: $350-800^{\circ} \mathrm{C}$ (cycle time $410 \mathrm{~s}$ ) and $350-900{ }^{\circ} \mathrm{C}$ (cycle time $460 \mathrm{~s}$ ). All fatigue tests were performed on an electromechanical test rig from Instron Ltd. using specimens with a circular cross section with $7 \mathrm{~mm}$ diameter and a Maytec capacitive extenso-meter with a gauge length of $10 \mathrm{~mm}$.

\section{Time and temperature dependent viscoplastic deformation}

\subsection{Experimental results}

Fig. 4 shows two representative stress histories of CLCF tests at $600{ }^{\circ} \mathrm{C}$ and $900{ }^{\circ} \mathrm{C}$ for both heats. The initial parts of the tests with the complex loading history are fully illustrated, while the following cyclic parts are only depicted with maximum and minimum peak stresses.

At $600{ }^{\circ} \mathrm{C}$ the age hardened condition shows a higher stress level than the solution annealed material. During the hold times only slight stress relaxation takes place. Strain rate effects could not be observed. The age hardened as well as the solution annealed specimens exhibit cyclic hardening (Fig. 4a). In contrast, visco-plastic deformation at $900{ }^{\circ} \mathrm{C}$ is almost independent of the preceding heat treatment.

Moreover, at $900{ }^{\circ} \mathrm{C}$ time dependent effects could be found with the help of the complex loading history. The
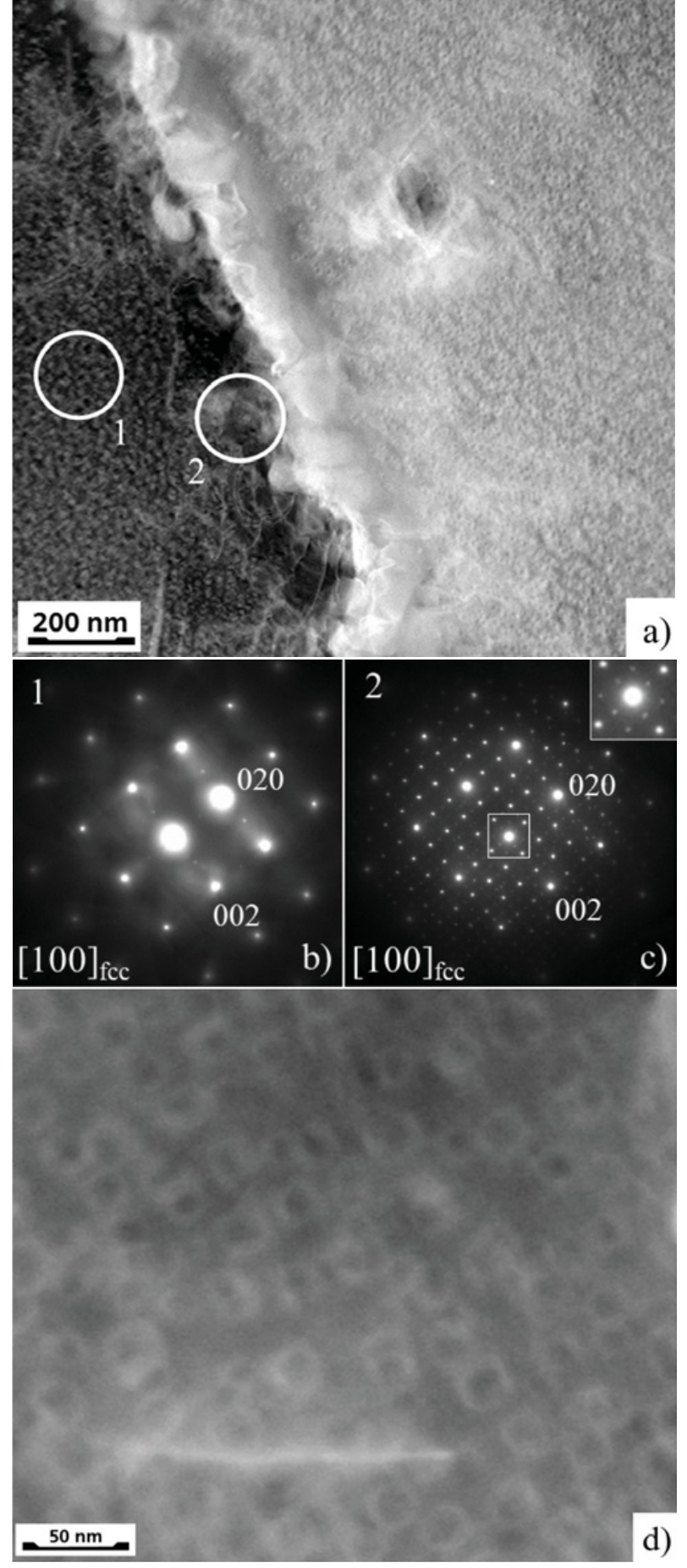

Figure 2. a) STEM image of AG material illustrating occupied grain boundary region and matrix, b) diffraction pattern of the $\gamma^{\prime}$ -precipitation in matrix, c) diffraction pattern of $\mathrm{M}_{23} \mathrm{C}_{6}$ carbide and $\mathrm{M}_{7} \mathrm{C}_{3}$. (Circles label positions where SAD patterns were obtained after tilting), d) $\gamma^{\prime}$-precipitation in matrix.

results of the cyclic part of the tests indicate little cyclic softening for both material conditions (Fig. 4b).

The peak stresses of the TMF tests are plotted in Fig. 5. Characteristic for the LG condition is that rapid cyclic hardening could be observed for the experiment with maximum temperature $800^{\circ} \mathrm{C}$. In steady state both material conditions exhibit nearly the same stress level 


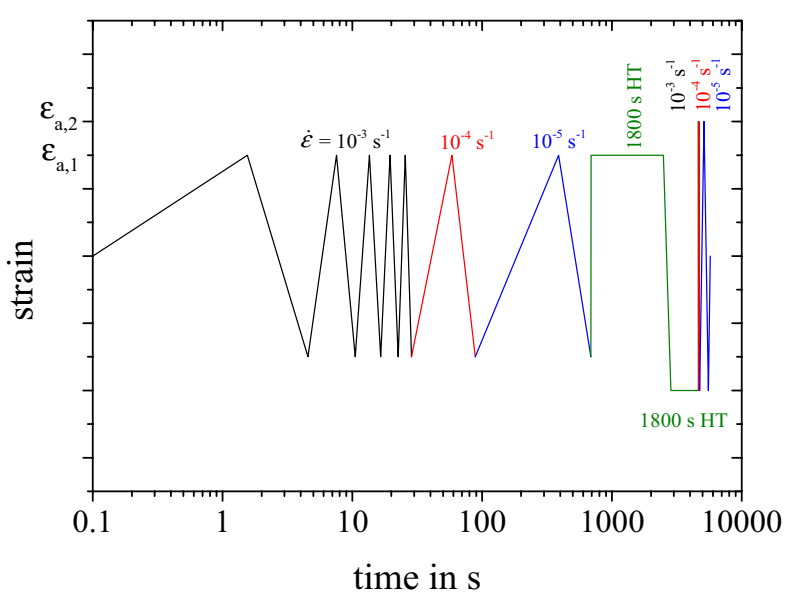

Figure 3. Complex loading in the CLCF tests.
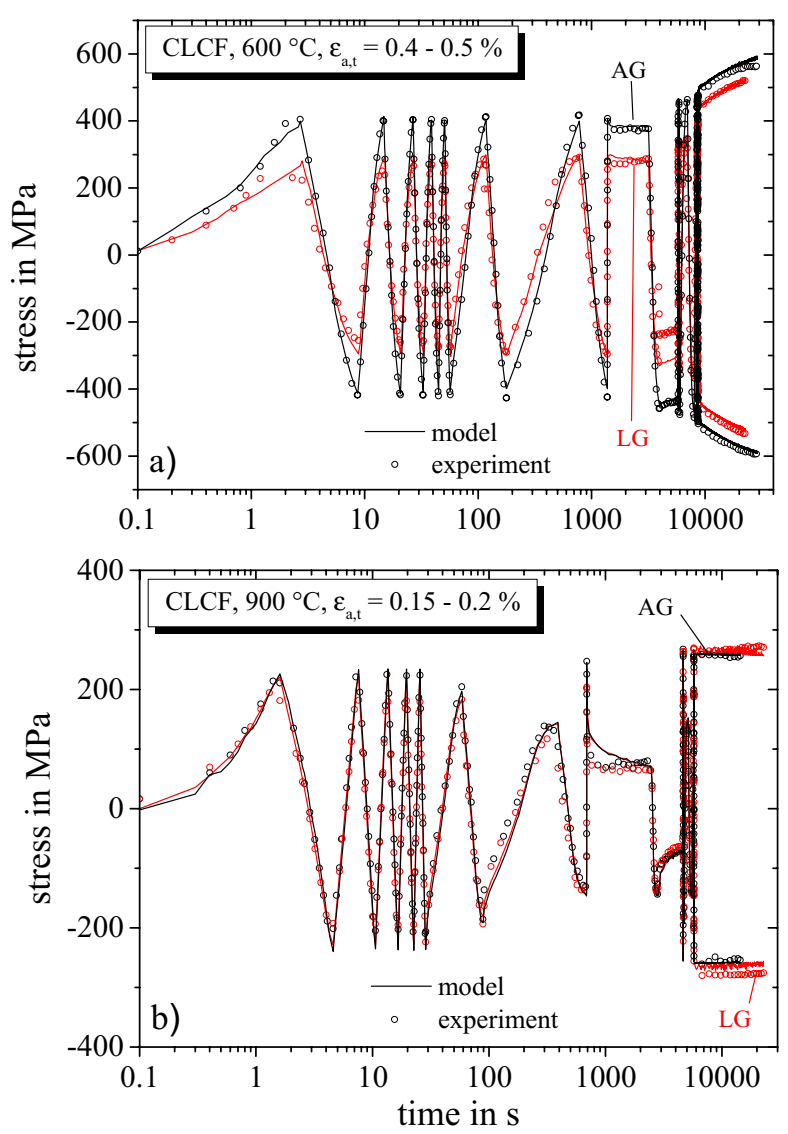

Figure 4. Stress response in isothermal CLCF tests for both material conditions at a) $600^{\circ} \mathrm{C}$, b) $900{ }^{\circ} \mathrm{C}$.

(Fig. 5a). If the maximum temperature is raised to $900^{\circ} \mathrm{C}$ the aged material softens rapidly whereas the solution annealed one shows little hardening. After a few cycles, both material conditions reach again the same stress level (Fig. 5b).

\subsection{Chaboche model}

Time and temperature dependent viscoplastic defor-mation is described by a Chaboche type model [6], which is able to describe tensile, creep and fatigue tests in a unified manner.
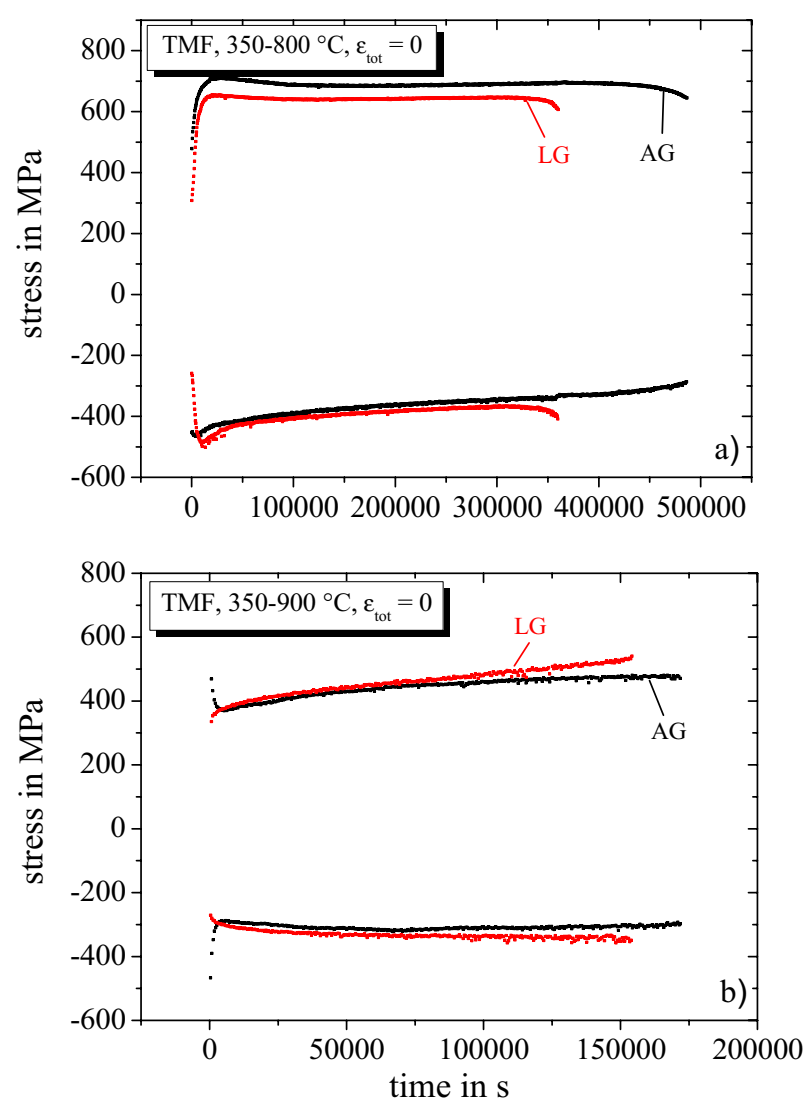

Figure 5. Peak stresses in TMF tests for both material conditions a) $350-800^{\circ} \mathrm{C}$, b) $350-900^{\circ} \mathrm{C}$.

In the following the constitutive equations of the model are presented in a one-dimensional formulation.

The total strain rate is split into an elastic, thermal and viscoplastic part:

$$
\dot{\varepsilon}=\frac{\sigma}{E}+\dot{\varepsilon}^{t h}+\dot{\varepsilon}^{v p} .
$$

The thermal strain rate $\dot{\varepsilon}^{\text {th }}$ is defined by the product of the differential thermal expansion coefficient $\alpha^{\text {th }}$ and the temperature rate:

$$
\dot{\varepsilon}^{t h}=\alpha^{t h} \Theta,
$$

The viscoplastic strain rate is given by:

$$
\dot{\varepsilon}^{v p}=\dot{p} \operatorname{sgn}(\sigma-X),
$$

with the equivalent viscoplastic strain rate:

$$
\dot{p}=\left(\frac{|\sigma-X|-\sigma_{\gamma}-\sigma_{M}}{K}\right)^{n},
$$

$K$ and $n$ are temperature dependent material parameters, $\sigma_{Y}$ is the initial yield strength and $\sigma_{M}$ is the isotropic hardening function obeying the evolution equation:

$$
\dot{\sigma}_{M}=b\left(Q_{\infty}-\sigma_{M}\right) \dot{p}-R_{i s o} \sigma_{M} .
$$

$b, Q_{\infty}$ and $R_{\text {iso }}$ are temperature dependent material parameters. The backstress $X$ is divided in two parts with index $i$, each following the evolution equation:

$$
\dot{X}_{t}=C_{i} \dot{\varepsilon}^{v p}-\gamma \Phi_{i} X_{i} \dot{p}-R_{K i n, i} X_{i}+\frac{1}{C_{i}} \frac{d c_{i}}{d \theta} X_{i} \Theta
$$


where cyclic hardening or softening is expressed by:

$$
\Phi_{i}=\Phi_{i, \infty}+\left(1-\Phi_{i, \infty}\right) \exp \left(-\omega_{i} p\right) .
$$

$C_{i}, \quad \gamma_{i}, \quad R_{k i n, i}, \quad \Phi_{i, \infty}$ and $\omega_{i}$ are temperature dependent material parameters.

The calibration of the Chaboche model parameters was accomplished by a least square fit to CLCF tests for all test temperatures separately (see Fig. 4). For the prediction of the thermo-cyclic tests the parameters were linearly interpolated in temperature. To account for the differences in viscoplastic material behavior of the two material conditions an internal variable $f$, representing the precipitate volume fraction was included in the model. It obeys the evolution equation:

$$
f^{\prime}=k_{0} \exp \left(-\frac{Q}{R O}\right) f^{\beta_{2}}\left(f_{e q}-f\right),
$$

where $Q$ is the activation energy for diffusion, $R$ is the universal gas constant and $k_{0}$ and $\beta_{2}$ are adjustable parameters. $f_{e q}$ is defined as the equilibrium volume fraction expressed by the following empirical equation:

$$
\begin{aligned}
& f_{e q}=f_{e q}^{*}-\exp \left(-\frac{\Theta_{\max }-\Theta}{\Theta_{0}}\right) \text { if } \Theta \leq \Theta_{\max } \\
& f_{e q}=0 \text { if } \Theta>\Theta_{\max },
\end{aligned}
$$

with the parameters $f_{e q}^{*}, \Theta_{\max }$ and $\Theta_{0}$. The adjustment of $\Theta_{\max }$ is based on experimental observations: The rapid softening of the AG material during thermo-cyclic loading between $350{ }^{\circ} \mathrm{C}$ and $900^{\circ} \mathrm{C}$ (see Fig. 5b) leads to the assumption that the precipitates dissolve at temperatures above about $850{ }^{\circ} \mathrm{C}$. Consequently, $\Theta_{\max }$ is set to $1123 \mathrm{~K}$. $\Theta_{0}$ and $f_{e q}^{*}$ are used as fit parameters and set to $\Theta_{0}=80 \mathrm{~K}$ and $f_{e q}^{*}=1$. The initial precipitate volume fraction of the LG material $f(t=0)_{L G}$ is set to zero while for the AG material $f(t=0)_{A G}=0.3$.

The precipitation hardening is considered as a purely isotropic hardening effect. The strengthening contribution is given by:

$$
\sigma_{p}=a_{p} f^{\beta_{1}}
$$

where $a_{p}$ and $\beta_{1}$ are adjustable parameters. Finally, Eq. (4) is replaced by:

$$
\dot{p}=\left(\frac{|\sigma-X|-\sigma_{\gamma}-\sigma_{M}-\sigma_{p}}{K}\right)^{n} .
$$

Figure 6 highlights the first cycles of the TMF tests in the temperature range from $350^{\circ} \mathrm{C}$ to $800^{\circ} \mathrm{C}$ and $350{ }^{\circ} \mathrm{C}$ to $900^{\circ} \mathrm{C}$ for the $\mathrm{LG}$ and $\mathrm{AG}$ condition, respectively. The open dots represent the experimental peak stresses, whereas the model response is shown with solid lines. Straight to the figures the development of the precipitate volume fraction is delineated. Cyclic hardening during the test with the LG material is well suited just like the cyclic softening in the TMF test with AG material and $900^{\circ} \mathrm{C}$ as maximum temperature.

\section{Mechanism based lifetime model}

In the present work a fracture-mechanics based model is used for the lifetime estimation under isothermal cyclic
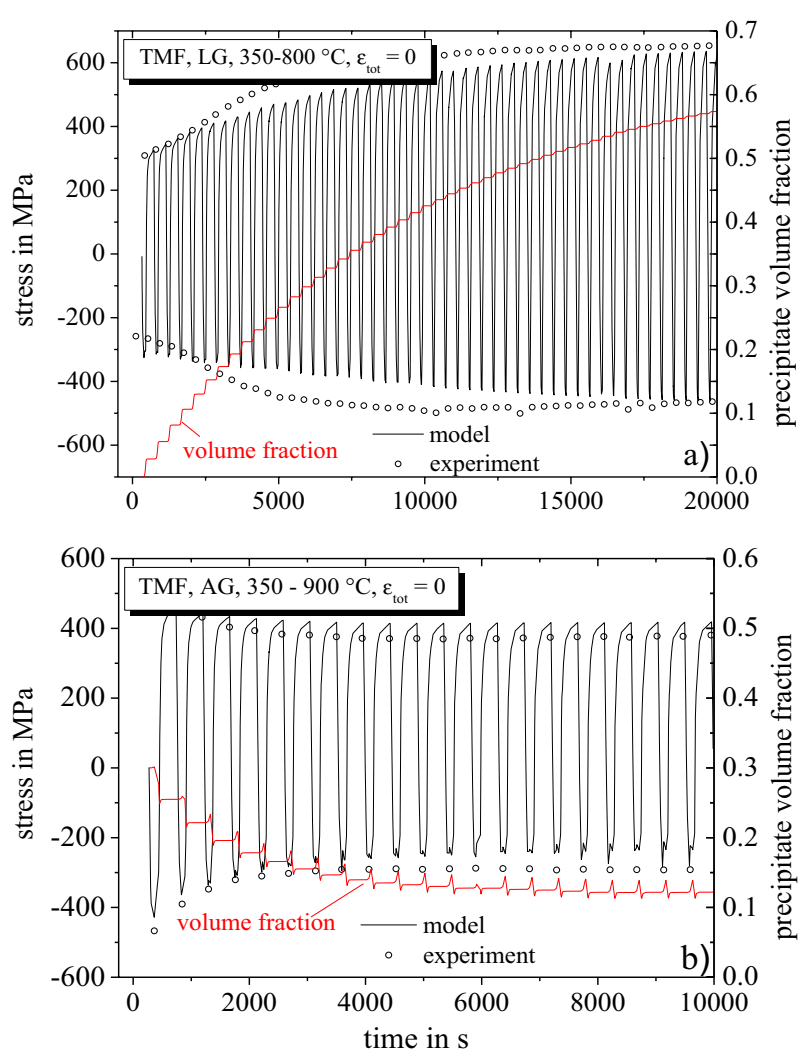

Figure 6. Model validation for different TMF tests a) LG condition $350-800^{\circ} \mathrm{C}$, b) AG condition $350-900^{\circ} \mathrm{C}$. Evolution of the precipitation volume fraction is illustrated straight to the figure.

and thermo-cyclic loading. The lifetime is determined by the initiation and growth of microcracks, with the latter dominating in the low-cycle fatigue range. Figure 7 illustrates a typical fracture surface of a fatigued C-263 specimen. Besides the principal crack growth direction, two further crack initiation sites are visible (Fig. 7a). Transgranular crack propagation was observed for all investigated AG specimens and loading histories while the residual fracture is mostly intergranular (Fig. 7b).

The general description of fatigue lifetime is based on the concept that the crack growth per cycle $d a / d N$ is proportional to the cyclic crack tip opening displacement $\triangle C T O D$ :

$$
\frac{d a}{d N}=\beta \Delta C T O D
$$

$\beta$ is a proportional factor which normally lies in the range of $1 / 3$ to 1 [7]. For a small crack in time independent material, an analytic solution for $\triangle C T O D$ is:

$$
\triangle C T O D=d_{n} \frac{Z_{D}}{\sigma_{c y}} a,
$$

where $\sigma_{c y}$ is the cyclic yield stress and $a$ the crack length. $d_{n}$ is given by the crack tip fields from Hutchinson [8], Rice and Rosengren [9] (HRR fields) as long as the material hardening can be described with a power law function [10]. In the present work $d_{n}$ is a third-order polynomial 

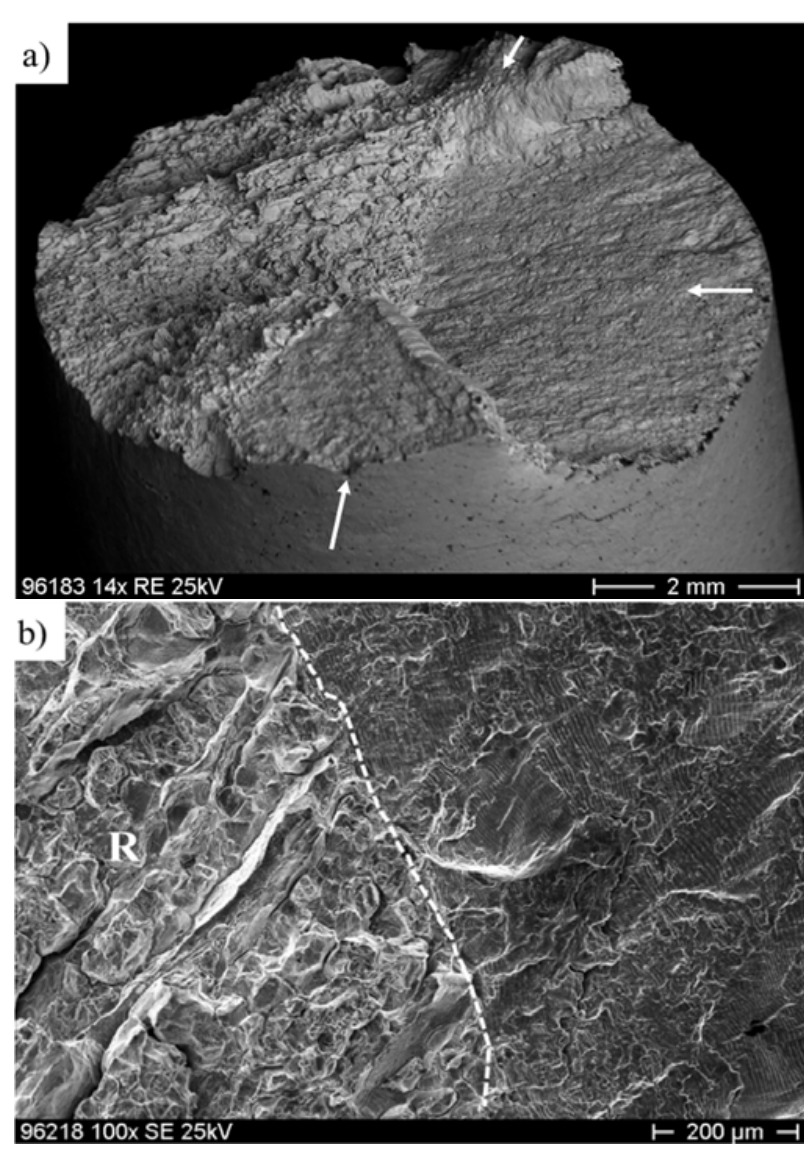

Figure 7. a) Fracture surface of AG specimen after TMF testing between $350{ }^{\circ} \mathrm{C}$ and $800^{\circ} \mathrm{C}$, b) detail of a) showing the transient zone from transgranular fatigue crack propagation mode (right side) to intergranular residual fracture (left side).

of the Ramberg-Osgood hardening exponent $N_{R}: \mathrm{d}_{n}=$ $0.78627+3.41692 N_{R}+6.11945 N_{R}^{2}-4.2227 N_{R}^{3}$, with coefficients adjusted to the numerical values given by Shih [11]. $Z_{D}$ is the damage parameter proposed by Heitmann [12]:

$$
\mathrm{Z}_{D}=1.45 \frac{\Delta \sigma_{e f f}^{2}}{E}+2.4 \frac{\Delta \sigma \Delta \varepsilon^{i n}}{\sqrt{1+N_{R}}} .
$$

To account for the crack closure effect the stress range in the elastic part of $\mathrm{Z}_{D}$ is replaced by the effective stress range $\Delta \sigma_{\text {eff }}$ according to:

$$
\Delta \sigma_{e f f}=\sigma_{\max }-\sigma_{o p}
$$

The crack opening stress $\sigma_{o p}$ could be determined with an empirical function propagated by Newman [13]. $\Delta \varepsilon^{i n}$ in Eq. (13) represents the inelastic strain range, including the viscoplastic and creep strain range.

Finally, the number of cycles to failure $\mathrm{N}_{\mathrm{f}}$ could be calculated by integrating Eq. (12):

$$
\mathrm{N}_{\mathrm{f}}=A\left(d_{n} \frac{Z_{D}}{\sigma_{c y}}\right)^{-1} \text { with } A=\frac{\ln \left(a_{f} / a_{0}\right)}{\beta} .
$$

Parameter $A$ involves the crack length till failure $a_{f}$ and the initial crack length $a_{0}$.

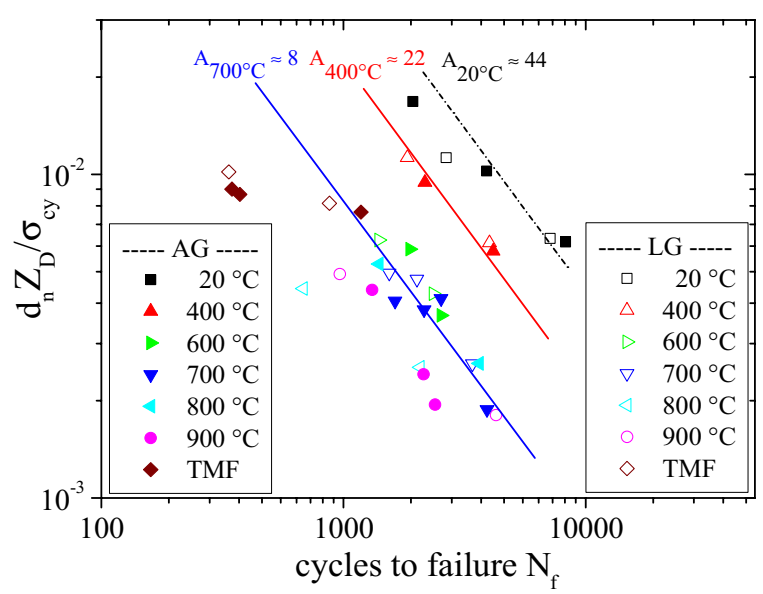

Figure 8. Calculated damage parameter as a function of the number of cycles to failure. Straight lines indicate the lifetime prediction for different values of A.

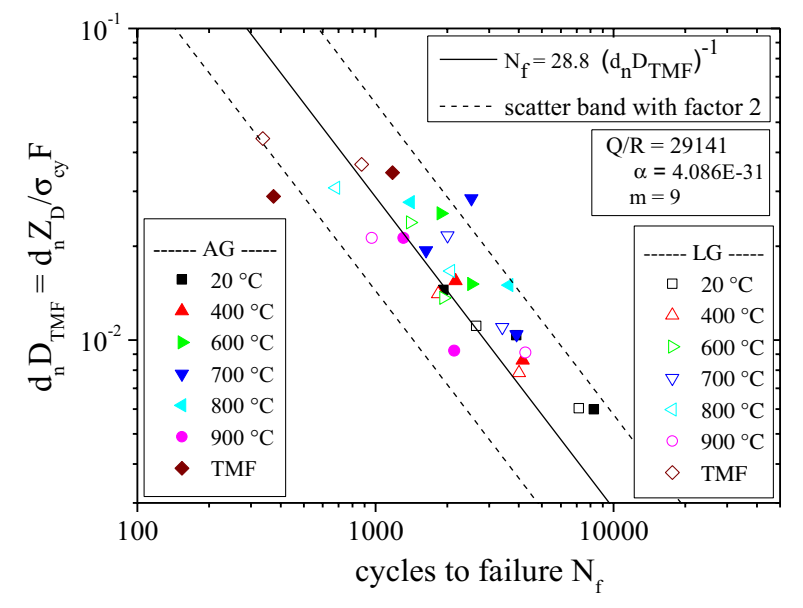

Figure 9. $\mathrm{D}_{\mathrm{TMF}}$ lifetime estimation.

Figure 8 shows the damage parameter $d_{n} Z_{D} / \sigma_{c y}$ for the data from CLCF and TMF tests as a function of the number of cycles to failure. The open symbols represent results from solution annealed specimens, closed symbols from age hardened specimens. Generally, under identical testing conditions the solution annealed material exhibits a slightly lower fatigue lifetime than the age hardened material. The indicated lines in Fig. 8 represent the lifetime prediction calculated with Eq. (16) for different values of $A$.

A consistent lifetime description can be achieved using the $\mathrm{D}_{\mathrm{TMF}}$ parameter which has been introduced by others [14]. Figure 9 illustrates the unified description of all CLCF and TMF tests in a scatter band with factor two.

\section{Discussion}

The investigations on $\mathrm{C}-263$ have illustrated that there is a marked influence of the heat treatment, via the microstructure, on the cyclic viscoplastic deformation. Due to the exposure of the solution annealed material at temperatures around $800{ }^{\circ} \mathrm{C}$, either during cyclic loading or during a thermal aging process, the material strength increases. This can mainly be explained by the 


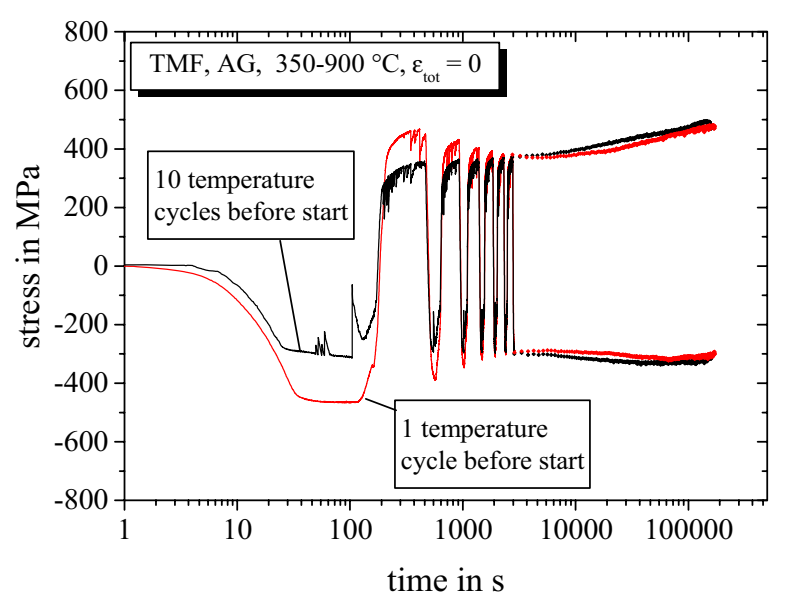

Figure 10. Comparison of TMF tests between 350 and $900{ }^{\circ} \mathrm{C}$ with AG material and different numbers of load-free temperature cycles before TMF testing.

$\gamma^{\prime}$-precipitation from the supersaturated solid solution (Fig. 2d). The experimental observations suggest that the precipitation kinetics is accelerated by a superimposed mechanical loading.

At very high temperatures, an initially solid solution strengthened and precipitation hardened microstructure softens quickly. Due to the dissolution of precipitates there is almost no difference in the deformation behavior between the solution annealed and age hardened material. Dissolution of precipitates for temperatures higher than about $850^{\circ} \mathrm{C}$ could be confirmed by the comparison of the TMF tests shown in Fig. 10. Therein, two stress histories are shown representing the results of TMF tests between $350{ }^{\circ} \mathrm{C}$ and $900^{\circ} \mathrm{C}$. Before starting the experiment, one specimen was subjected to a single and the other specimen to ten TMF temperature cycles with zero stress. As a result, higher peak stresses in the first TMF cycles could be observed. With increasing test time precipitates dissolve and both specimens exhibit the same response. The dissolution of $\gamma^{\prime}$ at higher temperatures has already been observed by other authors [3-5].

A consistent description of the viscoplastic deformation of the material in both conditions with a unique set of material parameters could be achieved by including an additional internal variable into the Chaboche model, representing the evolution of the precipitate microstructure in a phenomenological way. The additional parameters were adjusted in such a way that the cyclic hardening during TMF testing between $350{ }^{\circ} \mathrm{C}$ and $800^{\circ} \mathrm{C}$ as well as the cyclic softening during TMF testing between $350{ }^{\circ} \mathrm{C}$ and $900{ }^{\circ} \mathrm{C}$ could be uniformly described (see Fig. 6).

Independent from material and testing conditions, fatigue lifetime is well described with the fracturemechanics model based on the $\mathrm{D}_{\mathrm{TMF}}$ damage parameter. This is in agreement with e.g. [2] who achieved a unified lifetime description of the nickel-based Alloy 617B in different material conditions over a wide range of temperature and strain rate using the $D_{T M F}$ parameter.

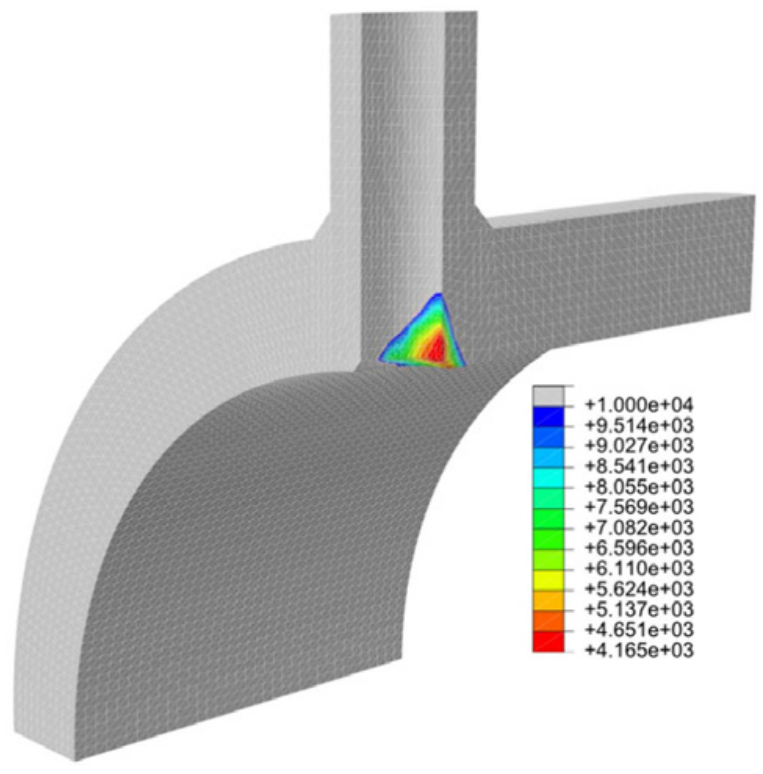

Figure 11. FEM lifetime calculation of steam pipe connection under thermomechanical fatigue loading.

\section{Application}

The described constitutive equations are implemented into a user defined material routine for finite element simulation. In Fig. 11 a typical lifetime calculation of a steam pipe connection is illustrated. The component was cyclically loaded between $300^{\circ} \mathrm{C}$ and $700{ }^{\circ} \mathrm{C}$ and loaded with an internal pressure varying from 1 to 295 bar. At the critical location a lifetime of about 4000 cycles is predicted.

\section{References}

[1] G. Maier, H. Riedel, C. Somsen, Int. J. Fatigue, 55, 126-135 (2013)

[2] G. Maier, PhD (KIT Karlsruhe, 2013)

[3] A. Manonukul, F.P.E. Dunne, D. Knowles, S. Williams, Int. J. Plasticity, 21, 1-20 (2005)

[4] A. Manonukul, F.P.E. Dunne, D. Knowles, Acta Materialia, 50, 2917-2931 (2002)

[5] Y.H. Zhang, D.M. Knowles, Proc. of 9th Int. Symposium on Superalloys, (Superalloys, Pennsylvania, 2000)

[6] J.L. Chaboche, Int. J. Plasticity, 5, 247-302 (1989)

[7] V. Tvergaard, ,J.W. Hutchinson, Proc. of 8th Int. Fatigue congress, (Fatigue, Stockholm, 2002)

[8] J.W. Hutchinson, J. Mech. Phys. Solids, 16, 13-31 (1968)

[9] J. R. Rice, J. F. Rosengren, J. Mech. Phys. Solids, 16, 1-12 (1968)

[10] C. F. Shih, J. Mech. Phys. Solids, 29, 305-326 (1981)

[11] C. F. Shih, MRL E-147 (Materials Research Laboratory, Brown University, 1983)

[12] H. Heitmann, PhD (RWTH Aachen, 1983)

[13] J.C. Newman, Int. J. Fracture, 24, 131-135, 1984

[14] W. Schmitt, R. Mohrmann, H. Riedel, A. Dietsche, A. Fischersworring-Bunk, Proc. of 8th Int. Fatigue congress, (Fatigue, Stockholm, 2002) 